\title{
Perubahan Klorofil, Luas Daun Spesifik, dan Efisiensi Penggunaan Cahaya Ubi Kayu pada Sistem Tumpang Sari dengan Jagung
}

\author{
Change of Chlorophyll, Specific Leaf area, and Light Use Efficiency of Cassava in Intercropping \\ with Maize
}

Suwarto*

\begin{abstract}
Departemen Agronomi dan Hortikultura, Fakultas Pertanian, Institut Pertanian Bogor (Bogor Agricultural University), J1. Meranti, Kampus IPB Darmaga, Bogor 16680, Indonesia

Telp.\&Faks.62-251-8629353 e-mail agronipb@indo.net.id
\end{abstract}

\begin{abstract}
This study aims to determine changes in chlorophyll content, specific leaf area (SLA), and light use efficiency (LUE) as a mechanism of physiological and morphological adaptation of cassava intercropped with maize. Cassava variety of Adira 1 has been planted in intercropping with maize varieties of Arjuna, Pioner 4, and Cargill 9 (with a population of 32,000; 48,000; 64,000, and 8,0000 plants $\mathrm{ha}^{-1}$ ); cassava is planted between rows of maize with a distance of $1 \mathrm{~m} \times 1 \mathrm{~m}$ (with a population of 10000 plants ha $\mathrm{a}^{-1}$ ). As a physiological adaptation mechanism, cassava which is planted intercropping increase light capture for photosynthesis by increasing the content of chlorophyll $a$ and chlorophyll $b$ as well as morphologically with increasing SLA. The average chlorophyll $a$ and $b$ of cassava in intercropping were 2.758 and $1.125 \mathrm{mg}$ g-1, whereas in monoculture were 2.032 and $0.750 \mathrm{mg} \mathrm{g}^{-1}$ or increased respectively $35.73 \%$ and $50.00 \%$. SLA of cassava increased from $309.5 \mathrm{~cm}^{2}$ $\mathrm{g}^{-1}$ in the monoculture became $406.3 \mathrm{~cm}^{2} \mathrm{~g}^{-1}$ in intercropping (increased by $31.27 \%$ ). The LUE of cassava at the beginning of growth during intercropping with maize is lower than the monoculture, but after maize is harvested the LUE increased so that the average LUE of cassava is the same during the whole periode of growth that is $0.0025 \mathrm{~kg} \mathrm{MJ}^{-1}$.
\end{abstract}

Keywords: mechanism, physiological, morphological, adaptation

\section{ABSTRAK}

Penelitian ini bertujuan untuk mengetahui perubahan kandungan klorofil, luas daun spesifik (SLA), dan efisiensi penggunaan cahaya (LUE) sebagai mekanisme adaptasi fisiologis dan morfologis ubi kayu yang ditumpangsarikan dengan jagung. Varietas ubi kayu Adira 1 telah ditanam tumpangsari dengan jagung varietas

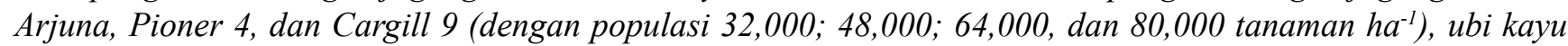
ditanam antara baris jagung dengan jarak $1 \mathrm{~m} \times 1 \mathrm{~m}$ (dengan populasi 10,000 tanaman ha ${ }^{-1}$ ). Sebagai mekanisme fisiologis adaptasi, ubi kayu yang ditanam tumpangsari menangkap peningkatan cahaya untuk fotosintesis dengan meningkatkan kandungan klorofil a dan klorofil b serta morfologis dengan SLA meningkat. Klorofil a dan b rata-rata ubi kayu dalam tumpangsari adalah 2.758 dan $1.125 \mathrm{mg} \mathrm{g}^{-1}$, sedangkan secara monokultur adalah 2.032 dan $0.750 \mathrm{mg} \mathrm{g}^{-1}$ atau meningkat masing-masing 35.73\% dan 50.00\%. SLA ubi kayu meningkat dari 309.5 $\mathrm{cm}^{2} \mathrm{~g}^{-1}$ secara monokultur menjadi $406.3 \mathrm{~cm} 2 \mathrm{~g}$-1 dalam tumpangsari (meningkat 31.27\%). Nilai LUE ubi kayu pada awal pertumbuhan selama tumpangsari dengan jagung lebih rendah dari monokultur, tetapi setelah jagung dipanen nilai LUE meningkat sehingga nilai LUE rata-rata dari ubi kayu adalah sama selama periode seluruh pertumbuhan yang $0.0025 \mathrm{~kg} \mathrm{MJ}^{-1}$.

Kata kunci: adaptasi, fisiologis, mekanisme, morfologi

\footnotetext{
* Penulis untuk korespondensi. e-mail:wrskm@yahoo.com
} 


\section{PENDAHULUAN}

Praktek penanaman tumpang sari (intercropping) antara ubi kayu dan jagung telah lazim dilaksanakan di wilayah sentra produksi ubi kayu di Indonesia. Willey dalam C.K. Ong (1996) menyatakan bawa efektivitas tumpang sari diantaranya dapat dinilai dari nisbah kesetaraan lahan atau land equivalent ratio (LER); bila LER $>1$ berarti tumpang sari lebih produktif dalam penggunaan lahan daripada monokultur.

Suwarto et al. (2005) melaporkan bahwa walaupun terjadi penurunan produktivitas masingmasing tanaman dibanding monokulturnya akibat adanya kompetisi, tumpang sari ubi kayu dan jagung menghasilkan nilai LER lebih dari 1. Artinya tumpang sari ubi kayu dan jagung mampu meningkatkan efisiensi penggunaan lahan.

Dalam tumpang sari terjadi interaksi antar tanaman, diantaranya berbentuk kompetisi dalam memperoleh cahaya, air, dan nutrisi. Ketika air dan nutrisi dalam kondisi tercukupi, kompetisi yang utama adalah dalam mendapatkan cahaya untuk proses fotosintesis. Ubi kayu yang ditanam bersamaan dengan jagung, selama pertumbuhannya hingga tanaman jagung dipanen memiliki tajuk yang lebih rendah. Akan tetapi dalam kondisi demikian, ubi kayu tetap mampu tumbuh dan berproduksi baik. Hal ini mengindikasikan adanya mekanisme tertentu yang memungkinkan ubi kayu mampu memanfaatkan cahaya yang terbatas untuk proses fotosintesis dalam rangka menghasilkan energi untuk pertumbuhannya.

Charles-Edward (1982) melaporkan bahwa secara umum daun-daun yang tumbuh di dalam lingkungan dengan tingkat cahaya datang (incident light levels) rendah adalah lebih tipis dan mungkin mempunyai permukaan daun yang lebih luas daripada daun yang tumbuh pada tingkat cahaya datang yang lebih tinggi; luas dan per satuan bobot kering yang dikenal dengan istilah specific leaf area (SLA) menjadi lebih besar.

Nilsen dan Orcutt (1996) melaporkan bahwa daun yang ternaungi memiliki rasio klorofil a:b lebih rendah daripada daun yang tidak ternaungi, yang menurut Jones (1992) hal ini merupakan respon fisiologis agar daun tetap mampu menyerap radiasi bergelombang panjang yang lebih banyak untuk fotosintesis.

Penelitian ini bertujuan untuk mengetahui perubahan khlorofil dan light use efficiency (LUE) sebagai mekanisme adaptasi fisiologis dan perubahan SLA sebagai mekanisme adaptasi morfologis ubi kayu dalam tumpang sari dengan jagung.

\section{BAHAN DAN METODE}

Percobaan dilakukan di Kebun Percobaan Sindangbarang, Institut Pertanian Bogor. Tiga varietas jagung yaitu Arjuna, Pioner 4, dan Cargill 9 ditanam pada populasi $32,000,48,000,64,000$, dan 80,000 tanaman ha-1 dengan jarak antar baris $1 \mathrm{~m}$. Ubi kayu (varietas Adira 1) ditumpangsarikan dengan menanamnya di antara barisan tanaman jagung, dengan jarak tanam $1 \mathrm{~m} \times 1 \mathrm{~m}$ atau populasi 10,000 tanaman ha $^{-1}$. Perlakuan kepadatan populasi diatur dalam Rancangan Kelompok Lengkap Teracak (RKLT). Sampel daun untuk klorofil diambil secara komposit dari ubi kayu yang ditanam pada berbagai populasi jagung tersebut pada saat ubi kayu berumur 3 bulan setelah tanam. Analisis kandungan klorofil a dan klorofil b dilakukan di laboratorium Research Group on Crop Improvement (RGCI), Departemen Agronomi dan Hortikultura, Fakultas Pertanian, IPB. Pengukuran SLA dilakukan pada fase sebelum pembentukan umbi, awal pengisian umbi, dan menjelang panen. Nilai SLA dihitung sebagai nisbah antara luas daun (L) dan bobot bahan keringnya (BKdaun); jadi, SLA = $\mathrm{L}$ : BKdaun, satuannya $\mathrm{cm}^{2} \mathrm{~g}^{-1}$. Nilai LUE dihitung sebagai nisbah antara produksi bahan kering pada suatu fase pertumbuhan terhadap jumlah radiasi surya yang diintersepsi/diabsorbsi (Qint) selama fase tersebut; sesuai hipotesis Monteith dan pernyataan Giauffret et al. (1991) bahwa terdapat hubungan linear antara perubahan bobot kering tanaman dengan perubahan jumlah radiasi surya yang diintersepsi/diabsorbsi. Jadi, LUE $=\Delta$ BKtot $/$ Qint dan dinyatakan dalam satuan $g$ $\mathrm{J}-1$ atau $\mathrm{kg} \mathrm{MJ}^{-1}$. Apabila $\Delta$ BKtot $\leq 0$, diasumsikan tidak terjadi pertumbuhan dan Lue bernilai 0 .

\section{HASIL DAN PEMBAHASAN}

\section{Kandungan Khlorofil Daun}

Tabel 1 menunjukkan bahwa klorofil a dan $b$ daun ubi kayu varietas Adira 1, baik yang ditumpang sarikan dengan jagung varietas Arjuna, Pioner 4, maupun Cargill 9 mengalami peningkatan. Ratarata konsentrasi khlorofil a dan b pada tumpang sari, masing-masing mencapai 2.758 dan $1.125 \mathrm{mg} \mathrm{g}^{-1}$ sedangkan pada monokultur adalah 2.032 dan 0.750 mg g-1 atau konsentrasinya meningkat $35.73 \%$ dan $50.00 \%$. Rasio khlorofil a/b pada tumpang sari adalah 2.45 , lebih rendah daripada monokulur yaitu 2.71. Hal ini sesuai dengan pernyataan Nilsen dan Orcutt (1996) bahwa daun yang ternaungi memiliki rasio khlorofil $\mathrm{a} / \mathrm{b}$ lebih tinggi daripada daun yang tidak tenaungi, yang menurut Jones (1992) hal ini merupakan respon 
atau mekanisme adaptasi fisiologis agar daun tetap mampu menyerap radiasi bergelombang panjang oleh khlorofil $b$ yang lebih banyak untuk fotosintesis. Hal di atas sesuai dengan hasil penelitian Kisman et al. (2007) bahwa pada tanaman kedelai terdapat beberapa karakter fisiologi yang dapat dijadikan penciri untuk adaptasi terhadap naungan yaitu kandungan klorofil $\mathrm{a}, \mathrm{b}$, dan total serta rasio klorofil $\mathrm{a} / \mathrm{b}$. Sebelumnya, Sopandi et al. (2003) juga menyatakan bahwa genotipe padi gogo yang tahan naungan mempunyai daun yang lebih tipis, kandungan khlorofil b yang lebih tinggi, dan rasio klorofil a/b yang lebih rendah. Respon yang sama juga terjadi pada tanaman talas sebagaimana dilaporkan oleh Djukri dan Purwoko (2003), talas yang dinaungi paranet $50 \%$ mempunyai khlorofil a dan $b$ yang lebih tinggi serta rasio klorofil $a / b$ yang lebih rendah.

\section{Luas Daun Spesifik}

Pada Tabel 1 terlihat bahwa sebaran klorofil a dan $\mathrm{b}\left(\mathrm{mg} \mathrm{cm}^{-2}\right)$ menunjukkan perbedaan tidak nyata antara ubi kayu pada tumpang sari dan monokultur. Klorofil a dan b pada tumpang sari 0.0068 dan 0.0027 $\mathrm{mg} \mathrm{cm}^{-2}$ dan pada monokultur 0.0066 dan 0.0024 $\mathrm{mg} \mathrm{cm} \mathrm{c}^{-2}$ atau meningkat $3.03 \%$ dan $12.50 \%$. Hal ini ternyata berkaitan dengan luas per bobot daun (SLA). Luas permukaan daun untuk bobot yang sama (SLA) pada ubi kayu tumpang sari lebih luas daripada monokultur. Rata-rata SLA ubi kayu monokultur $309.5 \mathrm{~cm}^{2} \mathrm{~g}^{-1}$ dan pada tumpang sari adalah $406.3 \mathrm{~cm}^{2}$ $\mathrm{g}^{-1}$ atau meningkat $31.27 \%$. Selain karakter fisiologi, menurut Kisman et al. (2007) juga terdapat karakter morfologi yang dapat digunakan sebagai penciri adaptasi kedelai terhadap naungan yaitu luas daun dan bobot daun spesifik (SLA). Analog dengan hal tersebut, daun ubi kayu yang lebih tipis, lebih luas, dan SLA yang lebih dapat dinyatakan sebagai upaya adaptasi tanaman ubi kayu agar mampu meningkatkan indeks luas daun sehingga semakin banyak radiasi yang dapat diintersepsi untuk fotosintesis dalam keadaan ternaungi. Menurut Charles-Edward et al. (1986) radiasi yang diintersepsi (Qint) untuk fotosintesis merupakan fungsi sederhana turunan dari indeks luas daun dan koefisien pemadaman. Djukri dan Purwoko (2003) melaporkan pula bahwa tanaman talas yang ternaungi paranet $50 \%$ mempunyai daun yang lebih luas daripada yang tidak ternaungi.

\section{Efisiensi Penggunaan Cahaya (Light Use Efficiency = LUE)}

Nilai LUE diperhitungkan sebagai hasil pembagian peningkatan bruto jumlah bahan kering yang diproduksi pada periode waktu tertentu dengan jumlah energi cahaya yang diintersepsi kanopi dalam periode waktu yang sama (Charles-Edward et al., 1986). Nilai LUE ubi kayu yang diukur pada periode waktu umur 3 ke 4, 4 ke 5, dan 6 ke 7 bulan setelah tanam (BST) tertera pada Tabel 2. Pada awal pertumbuhan (umur 3 ke 4 BST), ketika ubi kayu tumbuh bersama jagung, nilai LUE ubi kayu tumpang sari $(0.0009 \mathrm{~kg}$ $\mathrm{MJ}^{-1}$ ) lebih rendah daripada yang ditanam monokultur $\left(0.0035 \mathrm{~kg} \mathrm{MJ}^{-1}\right)$. Setelah jagung dipanen, pada periode pertumbuhan 4 ke 5 BST, nilai Lue ubi kayu meningkat dan lebih tinggi dari monokulturnya. Selanjutnya pada pada periode pertumbuhan 6 ke 7 BST hingga menjelang panen nilai LUE meningkat sehinggarata-rata selama pertumbuhan sama dengan monokultur yaitu $0.0025 \mathrm{~kg} \mathrm{MJ}^{-1}$. Nilai ini mendekati nilai-nilai LUE tanaman C4 yang dilaporkan oleh Fisher dan Foale dalam Charles-Edward et al. (1986). Nilai LUE yang rendah pada saat tumpang sari $(3 \mathrm{ke}$ 4 BST) adalah disebabkan oleh jumlah dan kualitas

Tabel 1. Kandungan klorofil daun ubi kayu pada pola tanam yang berbeda

\begin{tabular}{lccccc}
\hline Perlakuan & \multicolumn{2}{c}{ Klorofil } & \multicolumn{2}{c}{ SLA $\left.{ }^{*}\right)$} & \multicolumn{2}{c}{ Klorofil } \\
\cline { 2 - 6 } & $\mathrm{A}$ & $\mathrm{B}$ & $\left(\mathrm{cm}^{-1}\right)$ & $\mathrm{A}$ & $\mathrm{B}$ \\
\hline & \multicolumn{2}{c}{$\ldots . . \mathrm{mg} \mathrm{g}^{-1} \ldots .}$. & & $\ldots . \mathrm{mg} \mathrm{cm}^{-2} \ldots .$. \\
Monokultur & $2.032 \mathrm{a}$ & $0.750 \mathrm{a}$ & $309.5 \mathrm{a}$ & 0.007 & 0.002 \\
Tumpang sari & $2.758 \mathrm{~b}$ & $1.125 \mathrm{~b}$ & $406.3 \mathrm{~b}$ & 0.007 & 0.003 \\
Arjuna & $2.727 \mathrm{~b}$ & $1.112 \mathrm{~b}$ & $416.4 \mathrm{~b}$ & 0.007 & 0.003 \\
Pioner 4 & $2.795 \mathrm{~b}$ & $1.155 \mathrm{~b}$ & $409.1 \mathrm{~b}$ & 0.007 & 0.003 \\
Cargill 9 & $2.751 \mathrm{~b}$ & $1.108 \mathrm{~b}$ & $393.4 \mathrm{~b}$ & 0.007 & 0.003 \\
\hline
\end{tabular}

Keterangan: angka yang diikuti huruf yang sama pada kolom yang sama menunjukkan tidak berbeda nyata pada taraf 0.05 *) SLA = spesific leaf area (luas daun spesifik) 
Tabel 2. Nilai LUE ubi kayu pada pola tanam yang berbeda

\begin{tabular}{|c|c|c|c|c|}
\hline \multirow[t]{2}{*}{ Pola tanam } & \multicolumn{3}{|c|}{ Periode pengukuran (BST) } & \multirow[t]{2}{*}{ Rata-rata } \\
\hline & $3-4$ & 5-Apr & 7-Jun & \\
\hline & \multicolumn{4}{|c|}{$\ldots \ldots \ldots \ldots \ldots \mathrm{kg} \mathrm{MJ}^{-1} \ldots \ldots \ldots \ldots \ldots \ldots$} \\
\hline Monokultur & 0.004 & 0.002 & 0.002 & 0.003 \\
\hline Tumpang sari & 0.001 & 0.004 & 0.003 & 0.003 \\
\hline
\end{tabular}

radiasi yang dapat diintersepsi ubi kayu rendah. Pada pertanaman monokultur, radiasi cahaya yang datang di atas kanopi ubi kayu seluruhnya diintersepsi oleh ubi kayu, sedangkan pada pertanaman tumpang sari sebelum radiasi cahaya tiba di atas kanopi ubi kayu terlebih dahulu melewati tajuk jagung dan diintersepsi oleh kanopi jagung yang menaunginya (Gambar 1).

Sesuai dengan diagram skematik perubahan gelombang radiasi cahaya antara daun dan lingkungannya (Jones, 1992), pada pertanaman ubi kayu monokultur, radiasi cahaya yang datang di atasnya adalah radiasi cahaya langsung yang bergelombang pendek, sedangkan pada pertanaman tumpang sari radiasi yang tersedia bagi ubi kayu adalah radiasi baur/ difus yang bergelombang lebih panjang. Energi foton dari radiasi berhubungan dengan panjang gelombang. Menurut hukum Planck $(\mathrm{E}=h c / \lambda ; \mathrm{h}=$ tetapan Planck, $\mathrm{c}=$ kecepatan cahaya, dan $\lambda=$ panjang gelombang) energi radiasi bergelombang pendek lebih tinggi daripada yang bergelombang panjang (Jones, 1992). Jadi, radiasi yang tersedia bagi tanaman ubi kayu yang ditumpang sarikan dengan jagung, kualtitasnya yang lebih rendah dibanding pada monokultur. Akhirnya, per MJ radiasi yang datang pada pertanaman tumpang sari berenergi lebih kecil dan akan menghasilkan produk



Gambar 1. Jumlah radiasi yang tersedia untuk ubi kayu dalam sistem tumpang sari dengan jagung dari tiga varietas yang berbeda bahan kering ubi kayu yang lebih rendah daripada pertanaman monokultur, dan nilai Lue yang dihitung berdasarkan produk bahan kering tersebut menjadi lebih kecil (Tabel 2), hanya $0.0009 \mathrm{~kg} \mathrm{MJ}^{-1}$ pada saat pertumbuhan jagung maksimum (3 ke 4 BST).

Ketika jagung telah dipanen, pada umur ubi kayu 5 ke 6 BST, nilai LUE lebih tinggi daripada monokultur. Hal ini diduga oleh masih tingginya kandungan khlorofil a dan $\mathrm{b}$ sementara radiasi datang yang diintersepsi kanopi ubi kayu berjumlah lebih banyak dan berkualitas lebih tinggi (dominan cahaya bergelombang pendek) sehingga LUE meningkat. Pada periode selanjutnya (umur 6 ke 7 BST) nilai LUE yang hampir sama disebabkan oleh kandungan klorofil $a$ dan $b$, luas permukaan daun-daun yang tumbuh dari tanaman tumpang sari, dan radiasi yang datang di atas kanopi selama tidak ternaungi jagung sama dengan monokulturnya.

\section{KESIMPULAN}

Konsentrasi klorofil a dan b pada daun ubi kayu yang ditumpangsarikan dengan jagung mengalami peningkatan dibandingkan monokultur, namun sebarannya pada permukaan daun hampir merata karena luas daun spesifik (SLA) yang meningkat. Peningkatan kandungan klorofil dan luas permukaan daun yang menyebabkan meningkatnya efisiensi penggunaan cahaya (LUE) setelah jagung dipanen merupakan mekanisme adaptasi fisiologi dan morfologis ubi kayu selama dalam tumpang sari. Rata-rata LUE selama pertumbuhan, antara ubi kayu dan tumpang sari sama yaitu $0.0025 \mathrm{~kg} \mathrm{MJ}^{-1}$.

\section{DAFTAR PUSTAKA}

Charles-Edward, D.A. 1982. Physiological Determinants of Crop Growth. Academic Press. Sidney.

Charles-Edward, D.A., D. Doley, G.M. Rimmington. 1986. Modelling Plant Growth and Development. Academic Press. Sidney.

Ong, C.K. 1996. A Framework for Quantitying the Various Effects of Tree-Crop Interactions. $p 1$ - 23. In Chin K.Ong and P. Huxley (Eds.). Tree-Crop Interactions. CAB InternationalICRAF.

Djukri, B.S. Purwoko. 2003. Pengaruh naungan paranet terhadap sifat toleransi tanaman talas (Colocasia esculenta (L.) Schott). Ilmu Pertanian 10(2): $17-25$. 
Giauffert, C., R. Bonhomme, D. Dorvillez, M. Derieux. 1991. Conversion of intercepted radiation into arial dry biomass for three maize genotypes: influence of plant density. Maydica 36 : 25 -27 .

Jones, H.G. 1992. Plant and Microclimate. A quantitative approach to environmental plant physiology. 2nd ed. Cambridge Univ. Press.

Kisman, N. Khumaida, Trikoesoemaningtyas, Sobir, D. Sopandie. 2007. Karakter morfo-fisiologi daun penciri adaptasi kedelai terhadap intensitas cahaya rendah. Bul. Agron. (35): 96 - 102.
Nilsen, E.T., O.M. Orcutt. 1996. Physiology of Plants under Stress. Abiotic factors. John Wiley and Sons Inc. Kanada.

Sopandi, D., M.A. Chozin, S. Sastrosumarjo, T. Juhaeti, Sahardi. 2003. Toleransi terhadap naungan pada padi gogo. Hayati 10: $71-75$.

Suwarto, S. Yahya, M.A. Chozin, Handoko. 2005. Kompetisi Tanaman Jagung dan Ubi kayu dalam Sistem Tumpang Sari. Bul. Agron. 33(2):1-7 